\title{
O porto de São Francisco do Sul na dinâmica regional catarinense
}

Alcides Goularti Filho

Professor da UNESC (Universidade do Extremo Sul Catarinense)

\section{Palauras-chave}

Porto de São Francisco do Sul, modernização, economia regional catarinense.

\section{Classificação JEL N760,} N960.

\footnotetext{
Key words

Port of São Francisco do Sul, modernization, Santa Catarina regional economy. JEL Classification N760,

N960.
}

\section{Resumo}

O objetivo deste artigo é discutir a inserção do porto de São Francisco do Sul na dinâmica regional catarinense, com ênfase nas respostas dadas pelo porto à especialização, à diversificação e à integração da economia catarinense. Além da introdução e das considerações finais, o texto está dividido em três tópicos. O primeiro destaca a construção, os melhoramentos e os planos de expansão. Neste tópico serão abordadas as tentativas frustradas de construir o novo porto, as concessões legais, a criação como porto organizado, os investimentos feitos pela Petrobras e pelo governo estadual e os constantes estrangulamentos da estrutura portuária. No segundo tópico, será discutido o movimento de cargas do porto desde o início do século XX apresentando séries históricas de longa duração. E por último será apresentada uma periodização para a história econômica do porto de São Francisco do Sul, iniciando em 1908, quando foi realizado o primeiro estudo para a construção do novo porto.

\section{Abstract}

The objective of this article is to argue for the insertion of the port of São Francisco do Sul into the regional dynamics of the state of Santa Catarina with emphasis on the answers given by the port to the specialization, diversification and integration of the state's economy. Besides the introduction and final consideration, the text is divided into three parts. The first part examines the construction, the improvements and expansion plans. This topic looks at the frustrated attempts to build the new port, legal concessions, its creation as an organized port, investments made for Petrobras and the state government, and constant bottlenecks in port structure. After that, the port load movement from since the beginning of the $20^{\text {th }}$ century will be presented, as a long term bistorical series. And finally, an economic bistory periodization of the port of São Francisco do Sul will be presented, beginning in 1908, when the first study for the construction of the new port was carried out. 


\section{1_Introdução}

O surgimento dos portos em Santa Catarina tem a ver com a demarcação, a ocupação e o povoamento do território catarinense. A instalação dos trapiches para ancorar as embarcações era condição necessária para a manutenção dos principais núcleos populacionais que foram surgindo ao longo do litoral de Santa Catarina. Durante quase todo o século XIX, os portos de Laguna, Florianópolis (antigo Desterro), Itajaí e São Francisco do Sul não tinham grande expressão econômica nacional, isto é, sua importância era apenas local. Somente no final do século XIX é que os portos catarinenses passaram a ter mais destaque na economia brasileira. Durante a Primeira República, a divisão econômica dos portos catarinenses era a seguinte: Laguna e Imbituba exportavam carvão; Florianópolis, farinha; Itajaí, alimentos e madeira; e São Francisco do Sul, erva-mate e madeira. Esses produtos não eram expressivos na pauta de exportação brasileira, como café, borracha, algodão, cacau e açúcar.

Nos anos de 1950 e 1960, o porto de Itajaí consagrou-se como o porto madeireiro, o de Imbituba como carvoeiro, e os portos de Laguna, Florianópolis e de São Francisco do Sul passavam por momentos de crise, sem uma especialização definida. Com o fortalecimento da grande indústria catarinense e a consolidação dos setores eletro-metal-mecânico em Joinville e Jaraguá do Sul, têxtil-vestuário em Blumenau e Brusque, papel e celulose no Planalto, revestimentos cerâmicos em Criciúma e o complexo agroindustrial de carne no Oeste, os portos catarinenses ganharam um novo impulso.

Atualmente, Santa Catarina tem quatro portos com sistemas administrativos diferentes: o porto de São Francisco do Sul é administrado pelo governo estadual, o de Itajaí pela Prefeitura Municipal de Itajaí, o de Laguna pela Companhia Docas do Estado de São Paulo e o de Imbituba, que é um porto privado, pela Companhia Docas de Imbituba.

Num movimento lento de transformações estruturais, em dois séculos, o porto de São Francisco do Sul passou por profundas alterações. O porto ervateiro transformou-se em madeireiro, entrou em crise, recuperou-se com os granéis e hoje busca a diversificação. A cidade de São Francisco do Sul, fundada em 1658, está situada no litoral norte de Santa Catarina, nas margens da Baía da Babitonga, próximo à cidade de Joinville. Tal como Florianópolis e Laguna, São Francisco do Sul também era mais uma das vilas fundadas no litoral meridional da colônia. O mar era a única via de comunicação da vila com o resto da colônia. $\mathrm{O}$ porto e a vila nasceram 
juntos. Inicialmente, o porto era um ancoradouro natural, depois se transformou em trapiches, e atualmente é um porto organizado.

O objetivo deste texto é discutir como o porto de São Francisco do Sul foi respondendo às dinâmicas engendradas na economia catarinense, que inicialmente apresentava forte especialização regional, desdobrando em seguida numa diversificação produtiva e integrando-se no mercado interno e externo.

\section{Construção, melhoramentos e planos de expansão}

Neste item serão destacados os seguintes tópicos: a especialização regional e o sistema de transportes em Santa Catarina, as constantes tentativas de iniciar as obras do novo porto entre 1921 e 1934, a lenta construção entre 1941 e 1955, a criação do porto organizado em 1955, os investimentos realizados pela Petrobras em 1977 e pelo governo estadual em 1978 e os recentes estrangulamentos e a modernização nas últimas duas décadas.

\section{1_Especialização regional e sistema de transporte}

Podemos pensar a economia catarinense entre 1880 e 1945 como a fase de origem e crescimento do capital industrial. Nesse período predominava a pequena produção mercantil e a extração da erva-mate, madeira e carvão, além da indústria têxtil e alimentar.

A erva-mate extraída, transportada e beneficiada em Santa Catarina fazia parte do complexo ervateiro do Paraná. Parte da produção da erva era escoada via fluvial pelos rios Iguaçu e Negro, seguindo inicialmente pela Estrada Dona Francisca e mais tarde, pós-1917, pela linha ferroviária Porto União-São Francisco do Sul até a cidade de Joinville, onde era beneficiada e depois despachada pelo porto de São Francisco do Sul. No Paraná, destacavam-se a Estrada de Ferro do Paraná (Curitiba-Paranaguá) e os portos de Antonina e Paranaguá. Esse complexo começou a ser "desmontado" após 1930, com a queda nas exportações da erva-mate.

A madeira, basicamente da araucária, era extraída no oeste catarinense e escoada em balsas pelo rio Uruguai, para a Argentina, ou pela Estrada de Ferro São Paulo-Rio Grande, via linha Porto UniãoSão Francisco do Sul, passando pelas serrarias no planalto norte, chegando até o porto de São Francisco do Sul. Quando se esgotaram as reversas florestais da região, a partir dos anos de 1940, as atividades madeireiras deslocaram-se para o planalto serrano.

O carvão mineral era extraído das minas no sul catarinense e transportado pela Estrada de Ferro Dona Tereza Cristina até os portos de Laguna e Imbituba. Os ali- 
mentos e os têxteis concentravam-se nas cidades de Blumenau e Brusque, que comercializavam com várias cidades catarinenses e de outros Estados (CEAG/SC, 1980).

O aumento nas exportações destes dois produtos (erva-mate e madeira), sem as devidas melhorias no porto de São Francisco do Sul, gerava estrangulamentos constantes. Na década de 1910, houve considerável aumento na produção de erva-mate em Santa Catarina, que saltou de 5.761 toneladas em 1910, para 19.852 em 1919. E as exportações de madeira passaram de 626:402\$ réis em 1910, para 3.152:36\$ em 1919. O movimento de exportações no porto passou de 13.634 toneladas em 1911, para 72.307 em 1920 e de importações de 9.480 toneladas para 12.280 , respectivamente (Bossle, 1988). Portanto, era impossível manter a trajetória de crescimento das exportações de erva-mate e madeira sem profundos melhoramentos no porto de São Francisco do Sul.

Como conclusão desse movimento, é possível olhar para Santa Catarina nesse período como uma economia especializada em que cada porto atendia a sua binterland reforçando a própria especialização. $\mathrm{Na}$ tabela abaixo podemos acompanhar a participação das principais mercadorias exportadas por Santa Catarina, no período de 1895 a 1940.

Tabela 1_ Participação das principais mercadorias exportadas por Santa Catarina 1895-1940 (em \%)

\begin{tabular}{|c|c|c|c|c|c|c|c|c|c|}
\hline Ano & Erva-Mate & Madeira & Alimentos & Cereais & Tecido & Carvão & Soma & Outros & Total \\
\hline 1895 & 28,2 & 8,2 & 15,1 & 27,2 & & & 78,7 & 21,3 & 100,0 \\
\hline 1900 & 31,8 & 4,2 & 21,9 & 25,5 & 0,1 & & 83,5 & 16,5 & 100,0 \\
\hline 1905 & 24,6 & 9,2 & 21,4 & 19,0 & 2,3 & & 76,5 & 23,5 & 100,0 \\
\hline 1910 & 18,7 & 9,1 & 41,5 & 14,2 & & & 83,5 & 16,5 & 100,0 \\
\hline 1915 & 6,9 & 2,3 & 19,5 & 32,1 & 6,2 & & 67,1 & 32,9 & 100,0 \\
\hline 1920 & 13,2 & 10,0 & 14,4 & 13,8 & 5,7 & & 57,0 & 43,0 & 100,0 \\
\hline 1925 & 8,3 & 13,6 & 18,8 & 22,3 & 9,5 & 3,6 & 76,0 & 24,0 & 100,0 \\
\hline 1929 & 16,2 & 15,1 & 20,2 & 13,8 & 8,5 & 3,7 & 77,6 & 22,4 & 100,0 \\
\hline 1935 & 4,2 & 16,0 & 22,9 & 15,5 & 11,3 & 8,8 & 78,7 & 21,3 & 100,0 \\
\hline 1940 & 3,3 & 24,8 & 10,4 . & 10,8 . & 17,4 & 3,2 & 69,8 & 30,2 & 100,0 \\
\hline
\end{tabular}

Fonte: Goularti Filho, 2002 
De que maneira o porto de São Francisco do Sul respondeu a essa dinâmica imposta pela especialização regional catarinense? Inicialmente o porto estava ligado apenas à pequena cidade de São Francisco do Sul e suas instalações atendiam às demandas locais. O movimento de carga em São Francisco do Sul era feito nos vários trapiches espalhados nas margens da cidade. No início do século XX, havia o trapiche da Alfândega, o do Hoepcke, o do Mercado Público, o da Lloyd, o do Santista e o da Companhia da Estrada de Ferro São Paulo-Rio Grande. Com a fundação de Joinville e a expansão da economia ervateira, novas demandas surgiram exigindo melhoramentos e aquisição de novos equipamentos. A expansão das exportações de madeira, sem os devidos investimentos, fez com que a situação ficasse cada vez mais complicada. O governo catarinense, os empresários e a comunidade local exigiam a construção de outro porto fora da área urbana.

\subsection{As tentativas frutadas e as concessões}

O primeiro estudo realizado no século XX para a construção do outro porto de São Francisco do Sul afastado do centro da cidade foi elaborado em 1908, pelos engenheiros da Brazil Railway Company, a mesma companhia que construiu o ramal ferroviário Porto União-São Francisco do Sul da Estrada de Ferro São Paulo-Rio Grande. Neste estudo, foi elaborada uma sondagem em toda a região marítima que dá acesso à barra do norte até o interior da Baía da Babitonga, ficando definidas a máxima e a mínima profundidade das marés e a liberação para o tráfego de embarcações de até 27 pés de calado (Thiago, 1941).

Em 1912, foi concedida à Companhia Estrada de Ferro São Paulo-Rio Grande a autorização para construir e explorar uma estação marítima no porto de São Francisco do Sul sem ônus para a União. A Companhia deveria desobstruir o ancoradouro e dragar o canal através da lagoa Saguaçu, bem como desobstruir o rio Cachoeiras para a navegação de embarcações de até dois metros de calado, entre São Francisco do Sul e Joinville (Decreto 9.967/1912). As obras, porém, nunca foram iniciadas.

No final da década de 1910, o governo do Estado de Santa Catarina começou a exigir da Inspetoria Federal de Portos Rios e Canais (IFPRC) providências para a melhoria do porto de São Francisco do Sul que pudesse atender às demandas das atividades ervateiras e madeireiras. Em 1919, com base nas concessões feitas aos Estados do Paraná, do Maranhão e de Pernam- 
buco, o governo catarinense encaminhou um pedido à Inspetoria para que fosse feita a concessão das obras de melhoramento e de exploração para o governo estadual. Para tanto, a Lei ${ }^{\circ} 4.242$, de 1921, que fixou as despesas da União, definiu que a Inspetoria deveria mandar fazer os estudos para a construção do porto de São Francisco do Sul.

O Relatório dos Serviços Executados pela Comissão do Porto de São Francisco do Sul apresentado à Inspetoria reafirmava as exuberantes qualidades do porto de São Francisco do Sul, assegurando que, do Sul do Brasil, era o "melhor, mais amplo, mais abrigado e mais profundo do Estado, sendo por isso considerado como magnífico porto militar" (Inspetoria Federal de Portos, Rios e Canais, 1922, p. 5). Esses argumentos reforçaram a idéia da necessidade de dar mais atenção ao porto catarinense, tendo sido iniciados em setembro de 1921 os estudos de levantamento hidrográfico do porto e da barra (Brasil, 1922).

O Decreto $n^{\circ} 15.203$, de 1921, autorizou a celebração do contrato de construção das obras de melhoramento da barra e do novo porto de São Francisco do Sul por um prazo de setenta anos. Como no Decreto $n^{\circ} 15.203$ não havia prazos para o início das obras, então em 1925, pelo Decreto $n^{\circ} 16.896$, ficou determinado que as obras deveriam começar no máximo dois anos após a aprovação do contrato pelo Tribunal de Contas, e o prazo de entrega deveria ser de três anos após o início das obras.

Pelo fato de já haver em São Francisco do Sul um trapiche da firma Carl Hoepcke desde 1903, o projeto de construção do porto despertou o interesse de Carlos Hoepcke Júnior e Henrique Schloemam, que apresentaram ao governador Adolpho Konder, em março de 1927, um estudo para iniciar as obras (ASSENTAMENTO... 1927). As dificuldades financeiras eram o "principal estorvo" para que o Estado iniciasse a execução das obras (Ministério da Viação e Obras Públicas, 1928, p. 99). Finalmente, em 20 de junho de 1927, numa solenidade oficial, foi assentada a primeira pedra da obra do porto por Deodoro de Carvalho e Arnaldo S. Thiago (ASSENTAMENTO..., 1927).

Para a execução das obras, foi constituída, no dia 10 de março de 1928, na cidade de Florianópolis, a Companhia Porto de São Francisco. Alguns dos presentes na reunião de fundação foram: Adolpho Konder, Carlos Hoepcke Júnior, Carl Hoepcke, Max Hoepcke, Henrique Schloemam e Henrique da Silva Fents. Este último foi designado presidente da companhia, que tinha como principal objetivo a construção do porto (COMPAINHA..., 1928). 
De acordo com o decreto de 1925, a data prevista para a conclusão das obras era 20 de junho de 1930, o que não foi cumprido. Em 1930, as obras da construção do novo porto de São Francisco do Sul foram paralisadas, o mesmo ocorreu com as obras do porto de Itajaí e Laguna. Na verdade, esse movimento de paralisação de obras nos portos ocorreu em todo o Brasil, com a Revolução de 1930, que empossou Getúlio Vargas.

Diante da impossibilidade da conclusão das obras e com o esgotamento dos prazos, em 1930, foi apresentado pela Companhia Porto de São Francisco um novo projeto com um orçamento mais reduzido (Ministério da Viação e Obras Públicas, 1944, p. 156). Dados os descumprimentos dos contratos assinados junto ao governo do Estado de Santa Catarina, que não entregou as obras na data prevista, a União, por meio do Decreto $\mathrm{n}^{\circ} 24.292$, de 25 de maio de 1934, rescindiu o contrato. Um dos motivos expostos para a rescisão foi o fato de os serviços realizados pelo concessionário serem "insignificantes", não permitindo "sequer inaugurar a exploração comercial do porto" (Decreto $\left.\mathrm{n}^{\circ} 24.292 / 1934\right)$.

Para além do porto de São Francisco do Sul, como podemos pensar o sistema portuário brasileiro durante as primeiras décadas do século XX? O Brasil herdou do Império um sistema portuário fragmentado, alguns em precárias condições de uso insuficientes para suportar o aumento do fluxo de carga. Excluídos os maiores portos como Manaus, Recife, Rio de Janeiro e Santos, que também necessitavam de mais investimentos, muitos pleiteavam melhoramentos e outros mais segurança e recursos humanos (Lisboa, 1922). Durante o período de 1910 a 1934, que foi caracterizado pelo início da nacionalização dos problemas portuários com a centralização das tomadas de decisão, podemos destacar dois avanços para os portos: a criação da Inspetoria Federal dos Portos, Rios e Canais (IFPRC), em 1910, e a aprovação do Regulamento dos Portos Organizados, em 1922. Quando da aprovação do Regulamento, mesmo tendo como móvel da acumulação o capital mercantil agrário e exportador, a economia brasileira passava por um processo de diversificação econômica sem ser acompanhada das devidas melhorias nos portos (Barat, 1996).

Em 1930, o inspetor Hidelbrando de Araújo Góes publicou um livro/relatório onde expressou bem o espírito de mudança da época, pautado numa maior atuação do Estado na economia e na centralização das tomadas de decisão. Segundo Góes, o governo federal deveria abandonar a velha política de pensar o melhoramento dos portos, que era fragmentada e desarticula- 
da, para pensar uma nova política centralizada e hierarquizada. A falta de "planejamento" de uma política portuária nacional levou à superabundância de diversos portos na costa brasileira, alguns construídos de forma aleatória com pouca relação econômica com a sua binterland. Cada Estado, além de pleitear o melhoramento de seu porto principal, para atender a interesses locais, defendia a construção de outros portos para suprir demandas específicas. Muitas vezes, era ignorada a presença de um porto no Estado vizinho, que facilmente poderia atender às demandas específicas para contemporizar os compromissos políticos. Góes defendia que os portos deveriam ser classificados numa hierarquia, destacando os principais portos organizados e sua grande área de abrangência. Os pequenos portos tributários deveriam ter caráter "nitidamente temporário", e seu funcionamento dependeria da "marcha evolutiva das necessidades de cada um deles" (Góes, 1930, p. 7). Essa foi a visão que norteou a política portuária brasileira nas décadas seguintes, quando o Estado passou a centralizar, burocratizar e racionalizar ainda mais as suas funções.

\subsection{A lenta construção do porto}

Quando Getúlio Vargas visitou Santa Catarina, em março de 1940, ele esteve também na cidade de São Francisco do Sul, onde prometeu o reinício das obras do novo porto. Um ano após a sua visita, foi editado o Decreto $n^{\circ}$ 6.912, de $1^{\circ}$ de março de 1941, que novamente concedeu ao Estado de Santa Catarina a autorização para a construção e a exploração do porto de São Francisco do Sul por um prazo de setenta anos. $O$ decreto era rígido com os prazos das obras, que deveriam ser concluídas em seis anos e não poderiam sofrer interrupção por um período superior a três meses. O projeto foi elaborado pelo engenheiro Thiers de Lemos Fleming, e o maior problema para a construção do novo porto, segundo o engenheiro, era a localização das obras de acostagem, que poderiam ser feitas em todas as zonas da cidade que ia da Ponta do Raso ao trapiche da Alfândega (Decreto no 6.912/1941). Várias zonas foram estudadas e comparadas, até mesmo observando as áreas definidas nos projetos anteriores. Por fim, para a construção das instalações portuárias, foi escolhido o Saco da Laura. O dispositivo portuário definido foi a combinação do sistema "píers e darsenas" com o "cais e bacia". Ao todo, o projeto previa a construção de oito cais.

A extensão total do cais é assim de 2.154 metros a serem construidos por etapas de acordo com as necessidades do porto, com uma previsão muito larga para o futuro. 
[...] O cais número 8 oferecerá para of $u$ turo excelente a situação para meios que transportem mercadorias a granel, embora possa ser destinado para outros fins (Ministério da Viação e Obras Públicas, 1944, p. 156).

$\mathrm{Na}$ primeira etapa, seriam construídos oitocentos metros de cais, três armazéns, aterro da área conquistada, calçamento, linhas férreas, guindastes e outras dependências necessárias às atividades portuárias. No ano seguinte, em 1942, foram aprovados o projeto e o orçamento; porém, como as obras não começavam e, para ganhar tempo, em 1944, novamente foi prorrogado o prazo para início das obras (Decreto $n^{\circ} 10.313 / 1942$ e Decreto no 16.046/1944). Finalmente, no dia 21 de agosto de 1944, foram reiniciadas as obras. A empresa contratada foi a Companhia Construtora $\mathrm{Na}$ cional S/A., chefiada pelo engenheiro Leonardo Borthaisen, que ficou responsável pela construção do "cais acostável, o aterro da área conquistada, a dragagem e a execução dos diques de enrocamento para fechamento do terrapleno" (Ministério da Viação e Obras Públicas, 1948, p. 103).

Em 1950, as obras paralisaram novamente, e foi aprovado um novo orçamento para a construção do terceiro e do quarto cais (Decreto $\left.n^{\circ} 28.450 / 1950\right)$. Entre 1951 e 1952, foram construídos quase seiscentos metros de cais, os armazéns, o escri- tório para a administração, o desvio ferroviário e o calçamento da avenida que dá acesso ao porto. No ano de 1953, foi concluído o terceiro cais, e os armazéns foram entregues para os serviços de carga e descarga. Em 1954, as obras foram novamente paralisadas por falta de verba e o contrato com a Construtora Nacional foi rescindido e aberta nova licitação (Portobras, 1987 , p. 3).

\section{4_0 porto organizado}

Se até 1945 era possível ver Santa Catarina com uma economia especializada, nos anos seguintes essa realidade começou a se alterar substancialmente. No período 1945-1962, assiste-se, na economia catarinense, a uma verdadeira diversificação e ampliação da base produtiva. Há uma diversificação porque surgem outros setores como o de papel, papelão, pasta mecânica, cerâmico, metal-mecânico, material elétrico e indústrias ligadas ao setor de transporte. Há uma ampliação porque:

a. os setores como o de papel, papelão, pasta mecânica, móveis e metal-mecânico, que nasceram antes ou nos anos de 1930, aumentaram a sua produção e também surgiram indústrias;

b. os setores carbonífero e têxtil ampliaram a capacidade produtiva; 
c. a agricultura começou a se industrializar, transitando do complexo agrocomercial para o complexo agroindustrial.

Os setores com potencialidades mais dinâmicas, o metal-mecânico, o cerâmico e a produção de papel e pasta mecânica, nascem da pequena produção e voltamse para o mercado nacional, expandindose rapidamente, num momento em que a industrialização pesada estava num processo acelerado de expansão e consolidação. A pauta de exportação catarinense, porém, era composta em torno de 70,0\% de madeira (Tabela 2). As novas mercadorias produzidas em Santa Catarina (azulejos, papel, peças e equipamentos) eram destinadas ao mercado interno (Goularti Filho, 2002).

A queda exponencial das exportações de madeira a partir de 1970, que gerou uma capacidade ociosa no porto de São Francisco do Sul, coincidiu com a formação do complexo agroindustrial de carnes no Oeste, com a consolidação de grandes frigoríficos, que fomentou as exportações a partir da segunda metade dos anos de 1970. A ampliação das exportações catarinenses trouxe um novo fôlego para o porto de São Francisco do Sul, que se consolidava com o porto graneleiro. $\mathrm{Na}$ Tabela 3 podemos observar a queda substancial nas exportações de madeira e a ampliação de carnes e miudezas, derivado do complexo agroindustrial do oeste catarinense.

Tabela 2_Participação da madeira nas exportações em Santa Catarina 1945-1980

\begin{tabular}{|c|c|c|}
\hline Ano & Participação sobre o valor (em \%) & Em toneladas exportadas \\
\hline 1945 & 67,5 & 292.825 \\
\hline 1950 & 60,0 & 390.356 \\
\hline 1955 & 64,0 & 753.187 \\
\hline 1960 & 68,4 & 497.044 \\
\hline 1965 & 79,0 & 365.178 \\
\hline 1970 & 61,6 & 210.254 \\
\hline 1975 & 18,2 & 95.521 \\
\hline 1980 & 5,0 & 68.055 \\
\hline
\end{tabular}

Fonte: Goularti Filho (2002), Griggs (1974) e Kroetz (1975). 
Tabela 3_Participação das principais mercadorias exportadas por Santa Catarina 1970-1980 (em \%)

\begin{tabular}{|c|c|c|c|}
\hline Mercadorias & 1970 & 1975 & 1980 \\
\hline Açúcar refinado & - & 15,5 & 18,4 \\
\hline Farelo de soja & 2,1 & 4,3 & 16,6 \\
\hline Têxtil e vestuário & 1,5 & 16,5 & 13,8 \\
\hline Carnes e miudezas & - & 1,3 & 11,6 \\
\hline Fumo em folha & 8,9 & 16,1 & 9,2 \\
\hline Óleo de soja & - & 3,4 & 6,0 \\
\hline Madeira de pinho serrada & 57,5 & 14,6 & 5,0 \\
\hline Camarão fresco & 2,7 & - & 1,0 \\
\hline Obras de carpintaria & 4,1 & 3,6 & - \\
\hline Outros & 23,2 & 24,7 & 18,4 \\
\hline Total & 100,0 & 100,0 & 100,0 \\
\hline
\end{tabular}

Fonte: Goularti Filho (2002)

Se até a década de 1930 o porto de São Francisco do Sul atendia à especialização regional catarinense baseada na ervamate e pós-1930 na madeira, como o porto respondeu ao rápido processo de diversificação da estrutura produtiva catarinense?

Oficialmente, o porto foi inaugurado no dia $1^{\circ}$ de julho de 1955 , pelo governador Irineu Bornhausen, quando foram entregues dois cais com 550 metros e dois armazéns com $4.000 \mathrm{~m}^{2}$. Nesse mesmo ano, o governo do Estado sancionou a Lei $\mathrm{n}^{\circ} 1.404$, que criou e organizou a autarquia Administração do Porto de São Francisco do Sul (APSFS), que tinha como objetivo realizar a exploração comercial, executar as obras, conservar as instalações e manter o canal de acesso e a bacia de evolução em condições de tráfego. A APSFS ficaria sob a jurisdição da Secretaria da Viação e Obras Públicas (Lei Estadual no 1.404/1955).

Do período que vai do final dos anos de 1950 até a inauguração do Terminal Graneleiro, em outubro de 1978, o porto de São Francisco do Sul passou por uma longa crise. O principal motivo foi a queda nas exportações da madeira, que fez reduzir o movimento no porto, como podemos acompanhar na Tabela 2, quando a participação da madeira na pauta de exportações 
catarinenses passou de 753.187 toneladas, em 1955, para 95.521, em 1975. Durante o auge das exportações da madeira extraída no planalto serrano catarinense, nos anos de 1950 e 1960, o transporte ferroviário aos poucos foi sendo substituído pelo rodoviário. Dada a proximidade do planalto serrano, o porto de Itajaí transformou-se no maior porto madeireiro do País. A crise se abateu sobre o porto de Itajaí somente em meados dos anos de 1970, ao contrário de São Francisco, que já vinha lentamente se arrastando desde final dos anos de 1950.

Nesse mesmo período, décadas de 1950 e 1960, mais ao sul do Estado de Santa Catarina, o porto de Imbituba consolidavase como o porto carvoeiro do País, e o porto de Laguna se reestruturava para transformar-se num porto pesqueiro. Apesar da exportação de granel, nesse período, o porto de São Francisco do Sul ainda não tinha definido a sua especialização, algo que se foi configurando somente nos anos de 1970.

Na década de 1960, o governo estadual teve de solicitar autorização à Assembléia Legislativa para abrir crédito especial para cobertura de déficit de execução orçamentária para os anos de 1962, 1963, 1966, 1967 e 1968. Dada a crise financeira, foram realizadas poucas obras estruturais, e a conservação e os reparos na faixa do cais eram realizados com os "parcos recursos" da APSFS (Santa Catarina, 1967, p. 371). A
APSFS agonizava numa crise e não podia esperar do Estado mais recursos suplementares para projetos estruturais, uma vez que os recursos extras eram utilizados para cobrir os constantes déficits.

Do ponto de vista nacional, a partir de 1934 temos que pensar a evolução dos portos brasileiros dentro do "projeto nacional de industrialização", comandado pelo Estado brasileiro. Do ponto de vista institucional, ocorreram quatro mudanças: a transformação da Inspetoria de Portos Rios e Canais (IFPRC) em Departamento Nacional de Portos e Navegação (DNPN) em 1934, alterado em 1943 para Departamento Nacional de Portos, Rios e Canais (DNPRC), transformado em autarquia em 1963 como Departamento Nacional de Portos e Vias Navegáveis (DNPVN) e em Empresa de Portos do Brasil S/A. (Portobras) em 1975, uma empresa holding. Do ponto de vista jurídico, foram instituídos dois regimes portuários: o primeiro foi com o Decreto n ${ }^{\circ} 24.599$, em 1934, no qual o governo ficava autorizado a contratar para o melhoramento e exploração dos portos, por meio da concessão, os Estados ou as empresas privadas num prazo nunca superior a setenta anos; e o segundo, com o Decreto-Lei $n^{\circ} 749$, em 1969, que autorizava a União a formar sociedade de economia mista ou empresa pública destinada a explorar os portos, terminais e vias navegáveis. 
Durante os anos 1950 a 1980, passamos por vários regimes políticos, mas, até 1980, seguiu ininterruptamente um longo período de industrialização, e a década de 1980 foi de manutenção do parque industrial instalado. Nesse longo período de industrialização, o Estado brasileiro assumiu formas superiores de organização capitalista, orientando o processo de acumulação por meio do planejamento e do financiamento, além de políticas cambiais (orçamento cambial) e monetárias mais flexíveis voltadas para o crescimento. O Plano de Metas (19561961) e o II PND (1975-1978) são dois exemplos que cristalizaram os objetivos do Estado para a formação, segundo List (1986), de um sistema nacional de economia.

\section{5_Petrobras e COCAR - um novo fôlego}

O padrão de crescimento da economia catarinense alterou-se a partir de 1962 com a criação de um sistema de crédito estadual, com os investimentos em energia e transporte, comandados pelo Estado e com a consolidação do setor eletrometal-mecânico, liderado pelas médias e grandes indústrias. Mesmo nos setores tradicionais, várias firmas se consolidaram, incorporaram outras marcas, tornandose líderes nacionais. Internamente, o movimento geral da indústria catarinense passa a ser conduzido por grandes e médias empresas nos setores de alimentos, eletro-metal-mecânico, cerâmico, têxtilvestuário, papel e celulose, madeireiro, carbonífero, moveleiro, plástico, porcelanas e cristais. A mudança do padrão de crescimento em Santa Catarina só pode ser entendida, em primeira instância, pela mudança do padrão de acumulação em nível nacional, que tinha como tripé básico o capital estatal, o externo e o nacional. Em 1962, começa um novo período em Santa Catarina, quando o capital industrial passa a ser o móvel da acumulação capitalista. A modernização da agricultura, com a mutação do complexo agrocomercial para o complexo agroindustrial de carne, reforça e consolida o novo padrão de crescimento em Santa Catarina, comandado pelo Estado e pelas grandes e médias indústrias e agroindústrias (Goularti Filho, 2002).

O porto de São Francisco do Sul necessariamente teria que se adaptar a esse novo padrão de crescimento. A instalação do Terminal Marítimo de São Francisco do Sul (TEFRAN), obra complementar da Petrobras necessária para abastecer de petróleo a Refinaria Getúlio Vargas no Paraná, inaugurada em maio de 1977, trouxe certa folga financeira para o porto, já que o Terminal estava dentro da área portuária (Petrobras, 1978). A entrada de petróleo pelo sistema de monobóia, conectando o TEFRAN à refinaria por meio de um oleo- 
duto, significou aumento nas importações para o porto. Portanto, o movimento financeiro aumentou sem que houvesse esforço por parte do governo do Estado, reduzindo os constantes déficits (Camargo, 1988).

Contudo, o porto ainda continuava sofrendo com a queda nas exportações da madeira e sem um horizonte definido. Quando o governo federal, em 1971, criou o Programa de Corredores de Exportação e elegeu as áreas prioritárias para investimentos em infra-estrutura, os portos catarinenses ficaram todas de fora. A soja, que estava em franca expansão, seria escoada pelos portos de Paranaguá e Rio Grande (Ministério dos Transportes, 1971). Aliás, o porto de Paranaguá, que fica apenas a 36 quilômetros e que estava se definindo como um grande porto graneleiro, sempre foi um "espectro que rondava" o porto de São Francisco do Sul. Dentro das estratégias macronacionais de hierarquia portuária do Ministério dos Transportes, não eram necessários dois portos graneleiros próximos um do outro. No Sul do País, Paranaguá, que também tinha na sua adjacência o porto de Antonina, já atendia às demandas da fronteira agrícola. Além disso, Paraná tinha uma boa estrutura viária, com ferrovias e rodovias confluindo para o porto. Os demais portos catarinenses não concorriam diretamente com São Francisco, uma vez que Itajaí concentrava-se mais em cargas gerais, Imbituba, no carvão, e Laguna, na pesca.
Em 1975, a Empresa Brasileira de Planejamento de Transportes (GEIPOT) elaborou um estudo sobre as perspectivas de desenvolvimento do porto de São Francisco do Sul. A previsão era de que a movimentação de granéis sólidos passaria de 99.000 toneladas por ano, em 1974, para 527.000, em 1980. Contudo, as conclusões não foram animadoras. Ao contrário dos discursos ufanistas localistas, o estudo concluiu que a área de influência do porto restringia-se a Santa Catarina e a uma faixa do Rio Grande do Sul, já a do porto de Paranaguá tendia a crescer por três motivos:

a. pelo acesso ferroviário de Paranaguá ser de qualidade técnica superior;

b. pelo percurso rodoviário do oeste catarinense a Paranaguá ultrapassar somente em cinqüenta quilômetros o percurso a São Francisco do Sul;

c. pelo limitado calado de seis metros do porto catarinense.

Diante desse quadro, São Francisco do Sul não estava em

condicões de atender à demanda que lhe foi estimada devido às condições de armazenagem, dos equipamentos de manuseio e carga, das condiçoes e estado do cais (Empresa Brasileira de Planejamento de Transportes, 1975, p. 6).

São Francisco do Sul era apenas um porto complementar na região Sul. 
Quando ocorresse pressão da produção de soja sobre o sistema de armazenagem e transportes em Paranaguá e Rio Grande, parte da produção de trigo destinado ao Norte e ao Nordeste poderia ser desviada para São Francisco do Sul. Uma das medidas recomendadas para curto prazo era a adequação das instalações de armazenagem e equipamentos de manuseio, e para médio prazo a ampliação da capacidade de armazenagem de granéis sólidos. Sobre os equipamentos existentes, constatou-se o seguinte:

Os equipamentos existentes, de um modo geral, são antigos e têm vida útil ultrapassada estando na maioria em precário estado de conservação. A capacidade de embarque de granéis é muito baixa, 78 t/hora. Existe, além disso, três guindastes novos desmontados devido a que seus pesos são inadequados para o porto, exigindo dispêndio de reforço para sua utilização. Em sintese, o porto carece de um expressivo esforço de conservação e melhoramentos das suas instalaçoes atuais (Empresa Brasileira de Planejamento de Transportes, 1975, p. 47).

A situação do porto estava tão precária que a Portobras fez uma proposta para o governo estadual para que o porto fosse entregue à União. Seria criada uma sociedade de economia mista, a Companhia Docas de Santa Catarina, para que os problemas portuários fossem tratados com mais objetividade e "pelo ponto de vista portuário" (Portobras, 1987, p. 30). A Portobras teria a maioria acionária da Companhia, e o governo catarinense uma participação a ser equacionada. $\mathrm{Na}$ verdade, o sistema portuário catarinense estava passando por um momento crítico. $\mathrm{O}$ porto de Itajá sofria com a brusca queda nas exportações de madeira, $\mathrm{O}$ porto de Florianópolis havia sido desativado em definitivo e o porto pesqueiro de Laguna se arrastava numa crise que vinha desde os anos de 1950. O único porto que estava numa situação confortável era o de Imbituba, que recebia novos investimentos graças ao aumento da produção de carvão e se preparava para atender às demandas da indústria carboquímica catarinense.

Para suprir à crescente demanda das exportações de soja, a única saída para que o porto de São Francisco do Sul não ficasse numa situação inferior ao de Paranaguá seria criar uma infra-estrutura voltada para a exportação de granel sólido, com a construção de um terminal graneleiro com carregadores de navios. Em 1974, o GEIPOT e o DNPVN elaboraram o Plano Diretor Portuário do Brasil, que apresentava o Programa Decenal de Reaparelhamento e Expansão dos Portos para o período 19751984 e previa investimentos em 26 portos brasileiros. Para São Francisco do Sul, as obras programadas eram: 
Terminais para cereais (fase I), terminais para cereais (fase II), melhorias na importação granéis sólidos, recuperação do armazém 2 e aquisição de equipamentos (Ministério dos Transportes, 1974, p. 127).

A primeira fase, prevista para os anos de 1976 a 1978, foi executada. Para a construção do terminal, a Portobras arrendou para a APSFS uma área de $20.000 \mathrm{~m}^{2}$, e o Estado de Santa Catarina ficou responsável pelas obras por meio da recém-criada sociedade de economia mista Companhia Catarinense de Armazenamento (COCAR). O Terminal Graneleiro Irineu Bornhausen foi inaugurado em outubro de 1978 e tinha uma capacidade de 60.000 toneladas. Junto com a construção do terminal, a Portobras realizou obras de prolongamento do cais em 75 metros e reforço de 150 metros e financiou a instalação dos equipamentos automáticos para cereais (Santa Catarina, 1979). No ano seguinte, o porto começava a se preparar para a movimentação de contêiner com a construção de dois pátios destinados aos contêineres (Santa Catarina, 1980).

O bom desempenho exportador da economia catarinense nos anos de 1970 e início de 1980, que se concentrou principalmente no complexo agroindustrial, "salvou" o porto de São Francisco do Sul. O porto ajustou-se às novas demandas e, dentro da especialização regional catarinense, consolidava-se como o porto graneleiro catarinense.

\section{6_Estrangulamento e modernização}

Em 1987, a Portobras elaborou o Plano de Desenvolvimento Portuário envolvendo todos os portos brasileiros organizados. Todavia, as conclusões a respeito do porto de São Francisco do Sul continuaram não sendo animadoras. Após a construção do terminal graneleiro e do prolongamento da cais (75 metros), o porto não recebeu mais nenhum investimento estrutural nos anos de 1980; foram feitos apenas reparos, e a obra mais importante foi a construção dos pátios para contêineres. Por outro lado, o movimento de carga aumentava constantemente, dado o bom desempenho exportador de Santa Catarina. Com relação aos fatores limitantes dos serviços, segundo o Plano:

Os principais problemas operacionais estão ligados ao estado de obsolescência de muitos equipamentos e às limitações de calado, que restringem a operação, principalmente dos berços 101 e 201. Registram-se também as necessidades do porto, quanto a um pátio para estocagem de contêiner e equipamentos para manuseio e armazéns de carga geral e contêiner. O porto de São Francisco do Sul carece de novos berços de atracação especializados em contêineres e carga geral (Portobras, 1987, p. 30). 
O Plano concluiu que o porto não tinha condições de reduzir o nível de saturação sem implantar imediatamente outros berços. Além disso, deveriam ser feitas alterações administrativas e institucionais, e novamente volta à tona a idéia da criação de uma companhia docas para garantir o desempenho desejado. Se fosse imediatamente construído mais um berço e feitas as reformas necessárias, a situação estaria amenizada até 1990. Mas, em 1993, a situação estará novamente bastante crítica com relação ao tempo de espera no porto, quando se apresentará a necessidade de extensão desse cais para atender às operações de granéis sólidos e carga geral (Portobras, 1987, p. 1).

Em 1986, Santa Catarina entrou no Programa de Desenvolvimento do Setor de Transporte 1986-1989 (PRODEST) do Ministério dos Transportes, que ampliou para 16 o número de Corredores de Transportes. Com isso os portos de São Francisco do Sul e Itajaí passaram a ser prioritários na macroestratégia de investimentos do Ministério dos Transportes. São Francisco, em função das exportações de grãos, que estavam em ascensão no País, e Itajaí, para atender às exportações das indústrias catarinenses, como alimentos congelados, motores, revestimentos cerâmicos, calçados e têxtil-vestuário. Para o porto de São Francisco do Sul, ficaram definidas as seguintes ações: a. instalação de equipamento para movimentação de granel sólido;

b. reaparelhamento;

c. reconstrução e alargamento da faixa de cais (Brasil, 1986).

Após tantas recomendações para a construção de outro berço, em 4 de dezembro de 1987 foi assinado o convênio entre a Portobras e o governo de Santa Catarina, com a interveniência da firma C. R. Almeida Engenharia e Construções, para a execução das obras civis de ampliação e melhoramentos do porto de São Francisco do Sul. A ordem de serviço foi emitida pela Portobras em dezembro de 1988, e as obras foram completamente paralisadas em março de 1990, com a extinção da Portobras (Contrato no 005/87 - STO/SC e Convênio no 87/010/00 - Portobras).

No dia 15 de março de 1990, ou seja, no mesmo dia da posse do presidente Fernando Collor de Mello, foi baixada a Medida Provisória $n^{\circ} 151$, que extinguiu cinco autarquias, oito fundações, três empresas públicas e oito sociedades de economia mistas; entre as empresas, estava a Portobras. Após setenta anos de ampliação das funções institucionais dos diversos órgãos que foram criados para gerenciar os portos brasileiros, desde a IFPRC, numa simples medida provisória foi desmontada toda a estrutura da Portobras. Para os portos brasileiros, a extinção da Portobras marcou o 
início de uma confusão administrativa e uma rápida deterioração das estruturas. Do ponto de vista da hierarquia administrativa, as companhias docas e os demais departamentos simplesmente ficaram "soltos". Era o neoliberalismo nos portos brasileiros.

Mais do que o sistema portuário, o governo Collor pôs fim às políticas de transportes, inclusive com a extinção do Ministério dos Transportes, que foi reduzido a uma Secretaria dentro do Ministério da Infra-Estrutura, juntamente com as Comunicações e Minas e Energia. Se a estrutura portuária vinha se deteriorando nos anos 1980, com o fim da Portobras a situação se complicou mais ainda. As obras foram paralisadas, as licitações foram suspensas e os projetos foram encerrados. No quadro funcional da já extinta Portobras, a situação foi de espanto e de expectativa com o que viria pela frente. A solução imediata foi criar o Departamento de Portos dentro da Secretaria de Transportes, ou seja, a estrutura de uma grande empresa bolding transformou-se num departamento.

Os anos de 1990 também significaram épocas de profundas mudanças na economia catarinense, como a reestruturação da indústria cerâmica, o desmonte parcial do complexo carbonífero, a reestruturação patrimonial no complexo eletro-metalmecânico, a desverticalização e a retração no segmento têxtil-vestuário e a desnacionali- zação no complexo agroindustrial. A abertura comercial prejudicou vários segmentos industriais catarinenses com a quebra de cadeias produtivas e o fechamento de várias unidades fabris. É dentro desse cenário de ajustes, abertura e reestruturação que caminhou o porto de São Francisco do Sul nos anos de 1990 (Tabela 4).

Durante toda a década de 1990, o movimento de carga aumentava, e o porto de São Francisco do Sul se consolidava como um porto graneleiro, ao lado do de $\mathrm{Pa}$ ranaguá e Rio Grande. A estrutura, porém, estava saturada. A única ampliação realizada foi a do pátio de contêineres em 1994 (Santa Catarina, 1994, p. 205). Em 1998, com base na Lei ${ }^{\circ}$ 8.630/1993, foram retomadas as iniciativas para ampliar o cais e construir um terminal de carga para contêineres. A última ampliação de cais tinha sido realizada em 1978, 75 metros, e em junho de 1999, foram inaugurados mais 75 metros do berço 101 e mais 75 metros de correia transportadora. As obras foram realizadas pela APSFS juntamente com um pool de empresas: Ceval Alimentos, Moinho Serra Morena, Anaconda, Santista e Fetimport. Esse pool de empresas financiou as obras, que em troca poderiam utilizar os serviços do porto e dos terminais graneleiros da Companhia Integrada de Desenvolvimento Agrícola de Santa Catarina (CIDASC) (SÃO FRANCISCO..., 1999). 
Tabela 4_Participação das principais mercadorias exportadas por Santa Catarina 1985-2005 (em \%)

\begin{tabular}{|c|c|c|c|c|c|}
\hline Produtos & 1985 & 1990 & 1995 & 2000 & 2005 \\
\hline Carne congelada & 15,6 & 15,0 & 16,6 & 26,6 & 26,6 \\
\hline Móveis & 0,9 & 1,1 & 6,5 & 11,8 & 7,7 \\
\hline Moto compressor & 4,1 & 9,5 & 9,2 & 9,3 & 5,5 \\
\hline Motores elétricos & & 1,1 & 2,6 & 5,0 & 4,2 \\
\hline Pisos e azulejos & 0,9 & 2,5 & 3,8 & 5,3 & 3,8 \\
\hline Fumo em folha & 10,3 & 7,0 & 4,4 & 3,3 & 3,7 \\
\hline Papel Kraft & 1,3 & 2,1 & 3,4 & 3,7 & 2,9 \\
\hline Refrigeradores & 0,6 & 1,6 & 1,0 & 4,4 & 1,6 \\
\hline Ferro fundido/conexões & 2,4 & 1,3 & 1,5 & 0,5 & 0,7 \\
\hline Farelo de soja & 13,4 & 13,5 & 6,9 & 5,2 & 0,6 \\
\hline Calçados & 5,0 & 1,6 & 0,9 & 0,5 & 0,2 \\
\hline Louça e utensílios & 1,3 & & 0,5 & 0,5 & 0,2 \\
\hline Outros & 44,2 & 43,7 & 42,7 & 23,9 & 42,3 \\
\hline Total & 100,0 & 100,0 & 100,0 & 100,0 & 100,0 \\
\hline
\end{tabular}

Fonte: MDIC/SECEX/Sistema Aliceweb.

Dentro do Programa de Arrendamento de Áreas e Instalações Portuárias, em São Francisco do Sul, foi arrendada uma área para o Terminal Babitonga (antigo Terminal Portuário de São Francisco do Sul - TERFRAN), de $48.000 \mathrm{~m}^{2}$. Nessa área foi construído um terminal para produtos florestais renováveis e contêineres com um berço de atracações de 225 metros e calado de 10 metros. $\mathrm{O}$ atual $\mathrm{Pla}$ no de Desenvolvimento e Zoneamento Portuário prevê a construção de mais dois berços: o 401, que ficará conectado com o 101, e o 501, que se conectará ao 301. 
Quadro 1_Descrição da construção dos trechos de cais do porto de São Francisco do Sul

\begin{tabular}{|c|c|c|}
\hline Seção & Ano de construção & Comprimento (m) \\
\hline Trecho 1 & 1952 & 120 \\
\hline Trecho 2 & 1955 & 150 \\
\hline Trecho 3 & 1955 & 330 \\
\hline Trecho 4 (prolongamento - Portobras) & 1978 & 75 \\
\hline Trecho 5 (prolongamento - pool de empresas) & 1999 & 75 \\
\hline Trecho 6 (Terminal Babitonga) & 2004 & 225 \\
\hline
\end{tabular}

Fontes: Ministério dos Transportes (1994, p. 32). Dados fornecidos pela APSFS.

\section{3_ Movimento de cargas}

Ao longo do século XX, o movimento de carga no porto de São Francisco do Sul sofreu várias mudanças. Talvez o único dado que tenha se mantido estável foi o saldo comercial em toneladas, que sempre foi positivo. O movimento total de carga em toneladas na década de 1930 teve seu ritmo de crescimento reduzido, as importações praticamente estagnaram, e as exportações e a cabotagem tiveram pequeno aumento. Esse movimento tem a ver com a queda das exportações da erva-mate e o processo de industrialização do Brasil, que exigia maior integração do mercado interno. Após a inauguração oficial do porto em 1955, houve uma queda no movimento geral de cargas. Entre 1955 e 1965, a média foi de 330.243 toneladas e no período 1965 a 1975 caiu para 178.616 , ou seja, quase a metade, conforme Tabela 5. Nesse período, a maior queda se deu nas exportações de madeira e na cabotagem. Foram feitos poucos investimentos, e o porto entrou numa crise financeira, apresentando déficits constantes.

A expansão da fronteira agrícola, com os investimentos realizados (rodovias e colonização) e os subsídios liberados para o plantio da soja, aumentou consideravelmente a exportação de grãos e exigiu dos portos brasileiros profunda reestruturação. Dentro dos corredores de exportações, a prioridade foi dada a Paranaguá e Rio Grande, mas São Francisco do Sul também teve de ser beneficiada para atender à rápida expansão das exportações da soja. Internamente, em Santa Catarina, a agroindústria de carne crescia e demandava mais insumos, ao mesmo tempo em que 
começavam as exportações de frangos para o Oriente Médio. Portanto, reaparelhar o porto de São Francisco do Sul era condição sine qua non para manter o bom desempenho dos frigoríficos catarinenses e resolver os problemas de estrangulamento dos portos vizinhos. Com a construção dos terminais graneleiros e o prolongamento do cais, ambos inaugurados em 1978, o movimento de granel sólido passou de 101.721 toneladas, em 1975, para 691.720, em 1980, e
1.010.296, em 1985 (Tabela 5). Nesse momento, também entrou em operação o terminal da Petrobras, que gerava dividendos para o porto, e o começo da movimentação de granel líquido (excluindo petróleo). O movimento dos outros granéis líquidos, principalmente óleo vegetal, nos últimos cinco anos, com a entrada em operação de novos tanques da CIDASC, mais que dobrou, passando de 77.841 toneladas, em 2000, para 204.059, em 2006 (Tabela 5).

Tabela 5_ Movimento de cargas no porto de São Francisco do Sul - 1955-2006 (em toneladas)

\begin{tabular}{|c|c|c|c|c|}
\hline Ano & Granel sólido & $\begin{array}{c}\text { Granel líquido } \\
\text { (excluindo petróleo) }\end{array}$ & Carga geral & Total \\
\hline 1955 & 65.713 & & 250.713 & 316.426 \\
\hline 1960 & 59.998 & & 198.848 & 258.846 \\
\hline 1965 & 56.156 & & 125.486 & 181.642 \\
\hline 1970 & 45.549 & & 76.484 & 122.033 \\
\hline 1975 & 101.721 & & 66.571 & 168.292 \\
\hline 1980 & 691.720 & 55.925 & 84.312 & 831.957 \\
\hline 1985 & 1.010 .296 & 122.254 & 230.449 & 1.362 .999 \\
\hline 1990 & 1.428 .223 & 48.035 & 437.014 & 1.913 .272 \\
\hline 1995 & 1.522 .166 & 166.018 & 1.022 .822 & 2.711 .006 \\
\hline 2000 & 2.535 .087 & 77.841 & 1.936 .638 & 4.549 .566 \\
\hline 2006 & 3.895 .891 & 204.059 & 2.406 .347 & 6.506 .297 \\
\hline
\end{tabular}

Fonte: Estatística dos Portos DNPVN; Anuário Estatístico do Brasil, IBGE; Administração do Porto de São Francisco do Sul. 
Por outro lado, o movimento de carga geral só se recuperou da crise dos anos de 1960, somente com a construção dos pátios para contêineres no início dos anos de 1980. Em 1980, foram movimentados no porto 2.565 contêineres, passando para 13.796, em 1985, e 23.400, em 1990. Nos anos de 1990 e 2000, a trajetória do movimento de contêineres foi de ascensão constante, impulsionada principalmente pela construção do Terminal Babitonga, como pode ser visto na Tabela 6. O Terminal Babitonga, a Terlogs e os Terminais da CIDASC reestruturaram o porto de São Francisco do Sul e permitiram aumentos constantes no movimento de cargas.

\section{4_Uma periodização possível para a história econômica do porto de São Francisco do Sul}

Tomando como referência o ano de 1908, quando foi feito o primeiro estudo para a construção do novo porto, e observado o movimento da longa duração no porto de São Francisco do Sul, é possível pontuarmos cinco períodos, destacando a evolução estrutural, a movimentação de carga e a administração:

\section{8 a 1941 - em compasso de espera}

Entre concessões e tentativas frustradas de construção, o porto er- vateiro, ou melhor, os trapiches, seguiam a trajetória de crescimento. Nesse momento na economia catarinense, o capital industrial estava se formando, e o padrão de crescimento eram a pequena produção e o capital mercantil. O porto reforçava esse padrão escoando a produção de erva-mate e de madeira.

Tabela 6_Movimento de contêineres no porto de São Francisco do Sul $-1980-2006$

\begin{tabular}{|c|c|c|}
\hline Ano & Quantidade (unidade) & Peso ( $t$ ) \\
\hline 1980 & 2.565 & 10.863 \\
\hline 1982 & 5.858 & 13.622 \\
\hline 1984 & 9.817 & 79.257 \\
\hline 1986 & 14.254 & 125.579 \\
\hline 1988 & 20.922 & 213.104 \\
\hline 1990 & 23.400 & 247.981 \\
\hline 1992 & 30.888 & 334.780 \\
\hline 1994 & 37.762 & 452.319 \\
\hline 1996 & 67.239 & 971.564 \\
\hline 1998 & 78.348 & 1.197 .083 \\
\hline 2000 & 110.273 & 1.625 .039 \\
\hline 2002 & 160.187 & 2.359 .483 \\
\hline 2004 & 186.147 & 2.695 .648 \\
\hline 2006 & 174.064 & 2.520 .675 \\
\hline
\end{tabular}

Fonte: Administração do porto de São Francisco do Sul. 
1941 a 1955 - construção truncada

A nova concessão feita ao governo do Estado de Santa Catarina desencadeou a lenta construção do porto. São Francisco do Sul passou a se especializar em transporte de madeira. Nessa fase, a economia catarinense diversificava e ampliava a sua base produtiva com o surgimento de outras indústrias, e o porto se preparava para atender às novas mudanças.

1955 a 1978 - especialidade e crise

A queda brutal nas exportações da madeira fez com que o porto passasse por uma longa crise. Por outro lado, a expansão da fronteira agrícola no Brasil, destacando a plantação de soja, e a integração e consolidação do capital industrial em Santa Catarina exigiam mudanças estruturais no porto.

1978 a 1996 - porto graneleiro

A construção do terminal graneleiro da CIDASC foi decisiva para que o porto ingressasse numa nova trajetória de crescimento. Além dos granéis, o porto passou a movimentar a produção catarinense de manufaturados da região de Joinville, Jaraguá do Sul, São Bento do Sul, Mafra, Lages e Blumenau.
Após-1996 - expansão e privatização

A abertura comercial e a reprimarização da pauta de exportação brasileira exigiram novas mudanças nos portos brasileiros. Amparada pela Lei no 8.630/1993, a privatização chegou a São Francisco do Sul com o Terminal Babitonga e a Terlogs. Ambos contribuíam para desestrangular temporariamente o porto.

São Francisco do Sul é um porto integrado com a cidade e com a mesorregião do norte catarinense e movimenta carga de toda a região Sul do Brasil. O porto ervateiro transformou-se em madeireiro, entrou em crise, recuperou-se com os granéis e hoje busca a diversificação.

\section{5_Reflexões finais}

Pensando os portos brasileiros, desde o início do século XIX, são perceptíveis dois movimentos caminhando paralelos. O primeiro é que no sistema portuário brasileiro a oferta sempre andou a reboque da demanda, ou seja, os investimentos feitos nos portos (melhoramento, reaparelhamento e modernização) sempre foram insuficientes para atender ao volume crescente do comércio externo brasileiro. Os investimentos rapidamente matura- 
vam-se seguindo para um estrangulamento, exigindo mais e novos investimentos, porém, mais complexo e caro do que o anterior. Como a demanda anda à frente, o problema do estrangulamento é constantemente reposto num nível mais complexo. O segundo movimento é que, mesmo ao lado dos constantes estrangulamentos, foi se formando no Brasil um sistema portuário nacional integrado. Esse sistema acompanhou e contribuiu na formação do sistema nacional de economia. Rodovias, energia, telefonia, siderurgia, sistema de crédito e portos estão todos integrados e formam um sistema nacional de economia.

Já em relação a Santa Catarina, no último quartel do século XIX, as colônias catarinenses imprimiram um novo ritmo à economia regional e ajustaram os portos para escoarem a produção das pequenas atividades mercantis. A especialização regional catarinense durante a primeira metade do século XX, centrada na erva-mate, madeira, carvão e alimentos, fez com que os portos catarinenses também se especializassem em determinados segmentos. Com a diversificação produtiva da economia catarinense nos anos de 1940 e 1950, pautada na indústria metal-mecânica, cerâmica, papel e pasta mecânica e na formação do complexo agroindustrial, São Francisco do Sul teve de se ajustar às novas dinâmicas.
Com a integração e a consolidação da indústria catarinense a partir dos anos de 1960, comandadas pelo grande capital industrial e agroindustrial, e a queda nas exportações da madeira nos anos de 1970, o porto de São Francisco do Sul se especializou em granel. Os ajustes recessivos e a abertura comercial nos anos de 1990 colocaram novos desafios para o porto de São Francisco a partir da ampliação dos investimentos privados.

O porto já passou por momentos de crise, como a queda nas exportações da erva-mate e da madeira. Hoje, o porto vive um virtuoso período de crescimento pautado basicamente em dois pilares: a expansão do mercado externo brasileiro e os investimentos na modernização. 


\section{Referências bibliográficas}

\section{ASSEMBLEIA LEGISLATIVA DE SANTA CATARINA. \\ São Francisco do Sul manuscritos avulsos 1835-2000. Florianópolis: Divisão de Documentação/ Arquivo Permanente, 2004. \\ ASSENTAMENTO da primeira pedra. A Raz̃ão. São Francisco, 18 de junho de 1927.}

BARAT, Josef. O setor de transporte. In: AFFONSO, Rui de B. Álvares; SILVA, Pedro L. Barros (Orgs.). Empresas estatais e federação. São Paulo: FUNDAP, 1996.

BRASIL. Relatório apresentado ao Presidente da República dos Estados Unidos do Brasil Epitácio Pessoa pelo Ministro da Viação e Obras Públicas J. Pires do Rio no ano de 1921. Rio de Janeiro: Imprensa Nacional, 1922

BRASIL. Relatório apresentado ao Presidente da República dos Estados Unidos do Brasil Arthur da Silva Bernardes pelo Ministro da Viacão e Obras Públicas Francisco de Sá no ano de 1925. Rio de Janeiro: Imprensa Nacional, 1928.

BRASIL. PRODEST - Programa de Desenvolvimento do Setor de Transportes 1986-1989. Brasília: Ministério dos Transportes, 1986.
BRASIL. Decreto $n^{\circ}$ 9.967, de 26 de dezembro de 1912. Disponível em http://www.senado.gov.br/ servlets. Acesso em: 10 out. 2004.

BRASIL. Lei ñ 4.242, de 05 de fevereiro de 1921. Disponível em http://www.senado.gov.br/ servlets. Acesso em: 10 out. 2004.

BRASIL. Decreto $n^{\circ}$ 15.203, de 28 de dezembro de 1921. Disponível em http://www.senado.gov.br/ servlets. Acesso em: 10 out. 2004.

BRASIL. Decreto n $n^{\circ}$ 24.292, de 25 de maio de 1934. Disponível em http://www.senado.gov.br/servle ts. Acesso em: 10 out. 2004.

BRASIL. Decreto $n^{\circ}$ 6.912, de $1^{\circ} \mathrm{de}$ marco de 1941. Disponível em http://www.senado.gov.br/ servlets. Acesso em 10 de out. 2004.

BRASIL. Decreto $n^{\circ} 10.313$, de 22 de agosto de 1942. Disponível em http://www.senado.gov.br/ servlets. Acesso em: 10 out. 2004.

BRASIL. Decreto $n^{\circ} 16.046$, de 10 de junbo de 1944. Disponível em http://www.senado.gov.br/ servlets. Acesso em: 10 out. 2004.

BRASIL. Decreto $n^{\circ} 28.450$, de 31 de julho de 1950. Disponível em http://www.senado.gov.br/servle ts. Acesso em: 10 out. 2004.
BRASIL. Lei $n^{\circ} 8.630$, de 25 de fevereiro de 1993. Disponível em http://www.senado.gov.br/ servlets. Acesso em: 10 out. 2004.

BOSSLE, Ondina Pereira. História da industrialização catarinense: das origens à integração no desenvolvimento brasileiro. Florianópolis: CNI/FIESC, 1988.

CAMARGO, Luci Carme S.

Os portos concessionários no sistema portuário nacional: destaque São Francisco do Sul e Imbituba. Itajaí: FEPEVI, 1988.

(Monografia de Especialização).

CEAG/SC. Evolução

histórico-econômica de Santa Catarina: estudos das alterações estruturais (século XVII-1960). Florianópolis: CEBRAE/ CEAG-SC, 1980

COMPANHIA Porto de São Francisco do Sul. A Razão. São Francisco, 7 abr. 1928.

EMPRESA BRASILEIRA DE PLANEJAMENTO DE TRANSPORTES. Estudo sobre as perspectivas de desenvolvimento do porto de São Francisco do Sul. Brasília: Ministério dos Transportes, jun. 1975
GOES, Hidelbrando Araújo. Problemas portuários. Rio de Janeiro: Inspetoria de Porto, Rio e Canais, 1930.

GOULARTI FILHO, Alcides. Formação econômica de Santa Catarina. Florianópolis: Cidade Futura, 2002

GRIGGS, Rosemari Pozzi Eduardo. A madeira em Santa Catarina 1930-1970. Curitiba: UFPR, 1974. (Dissertação de mestrado).

INSPETORIA FEDERAL DE PORTOS, RIOS E CANAIS. Relatório dos serviços executados pela Comissão do Porto de São Francisco do Sul. São Francisco do Sul, p. 5, jun. 1922.

KROETZ, Lando Rogério. As estradas de ferro de Santa Catarina 1910-1960. Curitiba:

UFPR/Departamento de História, 1975. (Dissertação de mestrado)

LISBOA, Alfredo. Portos do Brasil. Rio de Janeiro: O Norte, 1922. 
MINISTÉRIO DA VIAÇÃO E OBRAS PÚBLICAS. Relatório dos serviços executados pela Inspetoria Federal de Portos, Rios e Canais apresentado ao Ministro da Viação e Obras Públicas pelo Inspetor Federal Hildebrando de Araújo Góes. Rio de Janeiro: Tipografia do Jornal do Commercio, 1928. (2 $2^{\mathrm{a}}$ parte).

MINISTÉRIO DA VIAÇÃO E OBRAS PÚBLICAS. Relatório dos serviços executados no ano de 1942 pelo Departamento Nacional de Portos e Navegação apresentado ao Ministro da Viação e Obras Públicas João de Mendonca Lima pelo Diretor Frederico Cezar Burlamaqui. Rio de Janeiro: Imprensa Nacional, 1944.

MINISTÉRIO DA VIAÇÃO E OBRAS PÚBLICAS. Relatório dos servicos executados no ano de 1944 pelo Departamento Nacional de Portos,

Rios e Canais apresentado ao Ministro da Viação e Obras Públicas João de Mendonça Lima pelo Diretor Hidelbrando de Araújo Góes. Rio de Janeiro: Imprensa Nacional, 1948.

MINISTÉRIO DOS

TRANSPORTES. Corredores de transportes. Rio de Janeiro: IPEA, 1971.

\section{MINISTÉRIO DOS}

TRANSPORTES. Plano Diretor

Portuário do Brasil. Brasília: GEIPOT; DNVPN, 1974.

\section{MINISTÉRIO DOS}

TRANSPORTES. Estudos

especificos para análise da movimentação portuária: São Francisco do Sul. GEIPOT: Brasília, 1994.
PETROBRAS. Terminal Marítimo de São Francisco do Sul/ TERFRAN. Rio de Janeiro: Serviço de Relações Públicas, jan. 1978.

PORTO de São Francisco. $A$ Razão. São Francisco do Sul, 17 maio 1919.

PORTO de São Francisco do Sul. A Razão. São Francisco, 16 mar. 1927.

PORTOBRAS. Plano de

Desenvolvimento Portuário: São

Francisco do Sul e Itajaí. Brasília, 1987, v. A3.

\section{SANTA CATARINA}

Mensagem apresentada à Assembléia Legislativa do Estado de Santa Catarina pelo Governador Ivo Silveira. Florianópolis, 1967.

SANTA CATARINA. Mensagem apresentada à Assembléia Legislativa do Estado de Santa Catarina pelo Governador Antônio Carlos Konder Reis. Florianópolis, 1977.

SANTA CATARINA. Mensagem apresentada à Assembléia Legislativa do Estado de Santa Catarina pelo Governado Jorge Konder Bornhausen. Florianópolis, 1979.

SANTA CATARINA. Mensagem apresentada à Assembléia Legislativa do Estado de Santa Catarina pelo Governador Jorge Konder Bornhausen. Florianópolis, 1980.

SANTA CATARINA. Mensagem apresentada à Assembléia Legislativa do Estado de Santa Catarina pelo Governador Vilson Kleinunbing. Florianópolis, 1994.
SANTA CATARINA. Lei

Estadual $n^{\circ} 1.404$, de 24 de novembro de 1955. Disponível em

http://www.alesc.sc.gov.br. Acesso em: 10 out. 2004.

SANTA CATARINA. Lei Estadual $n^{\circ} 3.278$, de $1^{\circ}$ de agosto de 1963. Disponível em http://www.alesc.sc.gov.br. Acesso em: 10 out. 2004.

SANTA CATARINA. Lei $n^{\circ} 3.345$, de 13 de novembro de 1963. Disponível em http://www.alesc. sc.gov.br. Acesso em: 10 out. 2004.

SANTA CATARINA. Lei n $n^{\circ} 3.926$, de 19 de dezembro de 1966. Disponível em http://www.alesc.sc.gov.br. Acesso em: 10 out. 2004.

SANTA CATARINA. Lei n $n^{\circ}$.059, de 06 de outubro de 1967. Disponível em http://www.alesc.sc.gov.br. Acesso em: 10 out. 2004.

SANTA CATARINA. Lei $n^{\circ} 4.206$, de 30 agosto de 1968. Disponível em http://www.alesc.sc.gov.br. Acesso em: 10 out. 2004

SÃO FRANCISCO inaugura mais obras para receber mais navios. Informativo dos Portos. Itajaí, n. 13, jun. 1999.

THIAGO, Arnaldo S. São Francisco: notícias estatísticodescritivas. Rio de Janeiro: IBGE, n. 19, 1941.

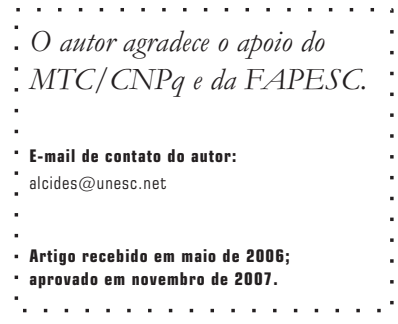

Brasitia, 1994.

Florianópolis, 1994. 
Anexo 1

Movimento de navios de cabotagem e de longo curso no porto de São Francisco do Sul - 1925-2006

\begin{tabular}{|c|c|c|}
\hline Ano & Navios de cabotagem & Navios de longo curso \\
\hline 1925 & 548 & 110 \\
\hline 1930 & 783 & 134 \\
\hline 1935 & 624 & 164 \\
\hline 1940 & 789 & 75 \\
\hline 1945 & 618 & 126 \\
\hline 1950 & 794 & 120 \\
\hline 1955 & 674 & 136 \\
\hline 1960 & 291 & 157 \\
\hline 1965 & 25 & 95 \\
\hline 1970 & 16 & 94 \\
\hline 1975 & 7 & 128 \\
\hline 1980 & 122 & 93 \\
\hline 1985 & 111 & 282 \\
\hline 1995 & 46 & 515 \\
\hline 2000 & 88 & 538 \\
\hline 2006 & & 741 \\
\hline
\end{tabular}

Fonte: Relatórios da IFPRC, DNPN, DNPRC; Estatística dos Portos DNPVN;

Administração do Porto de São Francisco do Sul. 
Movimento de cargas no porto de São Francisco do Sul - 1911-1950 (em toneladas)

\begin{tabular}{|c|c|c|c|}
\hline Ano & $\begin{array}{l}\text { Desembarque } \\
\text { (longo curso) }\end{array}$ & $\begin{array}{c}\text { Embarque } \\
\text { (longo curso) }\end{array}$ & Cabotagem \\
\hline 1911 & 9.480 & 13.634 & \\
\hline 1915 & 11.035 & 33.527 & \\
\hline 1920 & 12.280 & 72.307 & \\
\hline 1925 & 33.725 & 127.819 & 97.561 \\
\hline 1930 & 22.781 & 58.563 & 72.188 \\
\hline 1935 & 19.074 & 90.632 & 92.098 \\
\hline 1940 & 13.847 & 75.745 & 88.983 \\
\hline 1945 & 20.731 & 110.665 & 177.288 \\
\hline 1950 & 19.925 & 82.704 & \\
\hline
\end{tabular}

Fonte: Relatórios da IFPRC, DNPN, DNPRC; Estatística dos Portos DNPVN. 